\title{
Perivascular Epithelioid Cell Tumor (PEComa) of the Uterine Cervix in a Patient with Tuberous Sclerosis Complex: A Literature Review
}

\author{
Handan ÇELIK' ${ }^{\text {, Mehmet KEFELí }}{ }^{2}$, Mehmet ÇETINKAYA ${ }^{1}$, Levent YILDIZ $^{2}$ \\ Departments of 'Obstetrics and Gynecology and 'Pathology, Ondokuz Mayıs University, Faculty of Medicine, SAMSUN, TURKEY
}

\begin{abstract}
Perivascular epithelioid cell tumors (PEComa) are a rare type of mesenchymal tumor arising from perivascular epithelial cells. These tumor cells are a co-expression of both melanocytic and myogenic antigens, such as HMB 45 and smooth muscle actin, and at least in some patients, are located around vessels. PEComas has been reported at various sites, including visceral organs, soft tissue, the prostate gland and broad ligaments. In the female reproductive system, the uterine corpus is the most common site of involvement. Some cases are related to tuberous sclerosis complex. Cervical PEComa with tuberous sclerosis complex is presented in the case of a 41 year-old and the literature is reviewed. There have been only eight cases of cervical PEComas and only one other case associated with tuberous sclerosis complex reported to date.
\end{abstract}

Key Words: Perivascular epithelioid cell neoplasm, Uterine cervical neoplasm, Tuberous sclerosis

\section{INTRODUCTION}

The perivascular epithelioid cell (PEC) was first reported in 1943 by Apitz. It was described in renal angiomyolipoma and considered an "abnormal myoblast". In 1992, Bonetti et al. suggested the term "perivascular epithelioid" to define these cells (1). In 2002, the World Health Organization (WHO) designated PEComas as "mesenchymal tumors composed of histologically and immunohistochemically distinctive perivascular epithelioid cells" (2). It is a recognized as group of tumors containing PEC differentiation and includes renal or extra renal angiomyolipoma (AML), lymphangioleiomyomatosis (LAM), clear cell "sugar" tumor (CCST) of the lung, clear-cell myomelanocytic tumor of the falciform ligament, and a heterogeneous group of rare, clear cell tumors in other locations (2).

PEComa is a generally acknowledged as a family of tumors but there are also some uncertainties about their designation. Their differential diagnosis has been problematic and the association with epithelioid smooth muscle tumor is debatable. Because of the limited number of cases reported, the biological behavior of uterine PEComas is also uncertain, especially those of the cervix (3). Although most uterine PEComas are benign or have uncertain malignancy potential, malignant PEComas have been reported, although rarely (4). Only eight cases of PEComa in the cervix and one other case associated with

(Turk Patoloji Derg 2018, 34:82-86)

Received : 13.05.2014 Accepted : 26.06.2014 tuberous sclerosis complex (TSC) have been reported. We present the clinical and histopathological features of a cervical PEComa case and emphasize differential diagnosis and regular monitoring.

\section{CASE REPORT}

A 41-year-old virgin woman was admitted to hospital with a history of intermittent vaginal bleeding for fifteen days. She had a remarkable history of TSC, with epileptic seizures starting at the age of two, intellectual disability, radiological evidence of angiomyolipomas in the liver and kidney parenchyma, and cutaneous hypopigmented macula. She was taking antiepileptic drugs for seizures. Transabdominal sonography suggested a complex cervical mass. Magnetic resonance imaging confirmed a $4 \times 3.5 \mathrm{~cm}$ solid, cervical mass originating from the right, lateral wall of the cervix.

On the evening of hospitalization, she had excessive vaginal bleeding which necessitated emergency surgery. The intraoperative findings from the abdominal cavity and ovaries were normal. However, there was a solid cervical mass of approximately $4 \times 3 \mathrm{~cm}$ in diameter.

\section{Pathological Findings}

Macroscopically, the uterus measured $9 \times 5 \times 3.5 \mathrm{~cm}$ and there was a friable, solid mass arising from the cervix. The mass was measured at $4 \times 3.5 \times 2 \mathrm{~cm}$. The section of the mass was gray-white in color and had areas of hemorrhage.

Correspondence: Mehmet KEFELİ

Ondokuz Mayıs Üniversitesi, Tip Fakültesi,

Patoloji Anabilim Dalı, SAMSUN, TURKEY

E-mail: mehmetkefeli@gmail.com Phone: +90 3623121919 
Microscopically, the cervical mass had a small, infiltrative growth pattern (Figure 1). It consisted of a fascicular and sheet-like pattern of epithelioid cells that had well defined margins. Cellularity was moderate and there was a scant amount of intervening stroma which was rich in blood vessels. Areas of hemorrhage and focal necrosis constituted less than $5 \%$ of the tumor. Tumor cells were of medium size, round to polygonal in shape, eosinophilic, and had pale granular cytoplasm with round nuclei (Figure 2). There were some multinucleated cells and 'spider like' giant cells (Figure 3A,B), but they were rare. The mitotic count was 1 per 50 under high power field (HPF) and none of them was atypical. Lymphovascular invasion was not detected. Immunohistochemically, these cells were diffusely positive for HMB45 (dilution 1:100, clone HMB45, Thermo Scientific), vimentin (dilution 1:100, clone SP20, Thermo Scientific), desmin (dilution 1:150, clone D33, Thermo Scientific) and caldesmon (ready to use, clone h-CALD, Thermo Scientific), and focally positive for SMA (dilution 1:800, clone 1A4, Thermo Scientific) (Figure 4). The tumor cells were negative for cytokeratin (dilution 1:50, clone AE1/AE3, Thermo Scientific), CD10 (dilution 1:50, clone 56C6, Thermo Scientific), S-100 (Ready to use, clone 4C4.9, Thermo Scientific), CD-68 (dilution 1:1000, clone Kp-1, Thermo Scientific) and CD34 (dilution 1:400, clone QBEnd/10, Novocastra). The Ki67 (ready to use, clone SP6, Thermo Scientific) index was 3-4 \%. The endometrium, myometrium and both ovaries were free of the tumor. The final histological diagnosis was PEComa arising from the cervix. Close surveillance of the patient for the following three years produced no evidence of recurrence or metastasis.

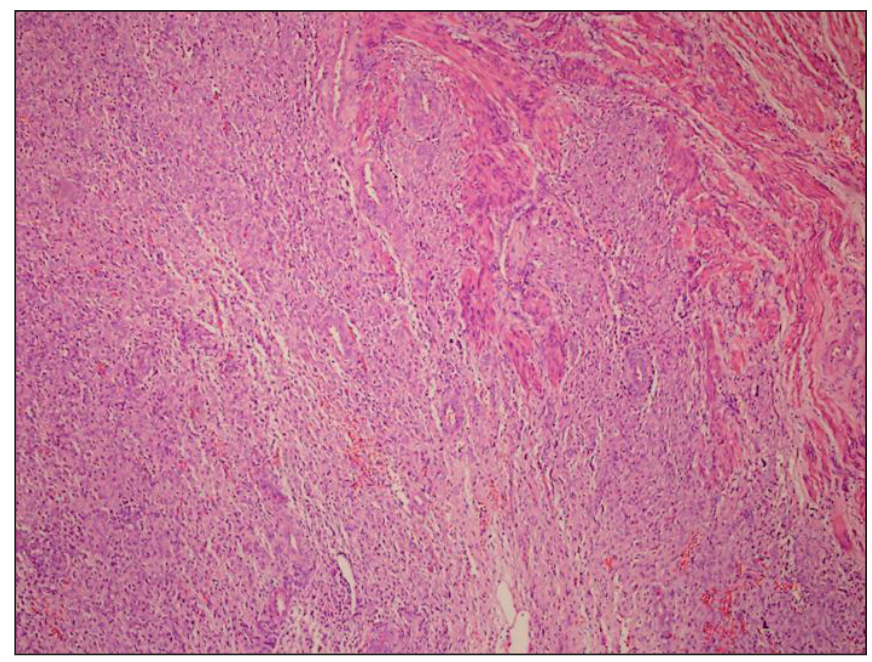

Figure 1: Infiltrative pattern of tumor mass to cervical stroma (H\&E, x100).

\section{DISCUSSION}

In 1991, it was reported that renal AML and CCST of the lung displayed HMB45 immunoreactivity, which is a marker for tumors displaying melanocytic differentiation (5). In addition to immunophenotypic similarities, both tumors share a distinctive cell type, with an epithelioid to spindle cell shape, a clear or eosinophilic granular cytoplasm, and a perivascular distribution (4). Bonetti et al. reported the same histopathologic and immunohistochemical findings in LAM of the lung. They suggested that CCST, AML and LAM are in the same group of tumors because they originate from the same cell type, which is the "perivascular epithelioid cell"(6).

The normal counterpart and origin of PEC is unknown. It has been hypothesised that these cells originate from melanocytic cells, smooth muscle cells, pericytic cells or perivascular cells, or originate from undifferentiated cells of the neural crest that are positive with both melanocytic and myogenic antigens (1). Fukunaga proposed that primitive mesenchymal cells could be differentiating towards both smooth muscle and HMB45 positive PEC and that the degree of differentiation may differ between cases. Therefore, some tumors may show pure PEC or pure smooth muscle differentiation, and some of them may show incomplete differentiation (3).

Until the last few years, uterine epithelioid mesenchymal tumors were thought to be epithelioid smooth muscle tumors. Recently, it was reported that uterine epithelioid tumors were comprised focally or entirely of HMB45 positive cells. These cells have a histopathological and

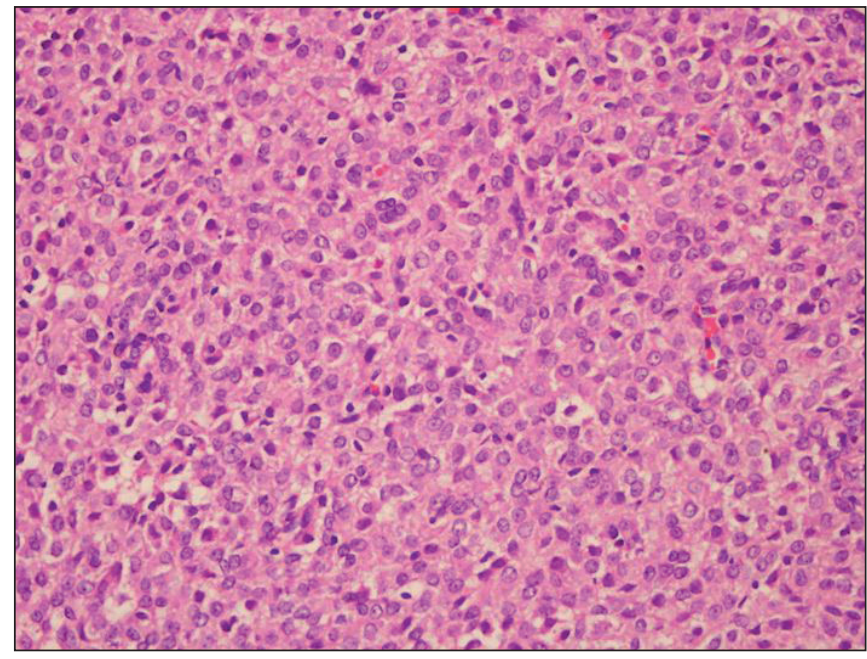

Figure 2: Sheet-like pattern of epithelioid tumor cells which has eosinophilic pale granular cytoplasm with round shaped nucleus (H\&E, x400). 

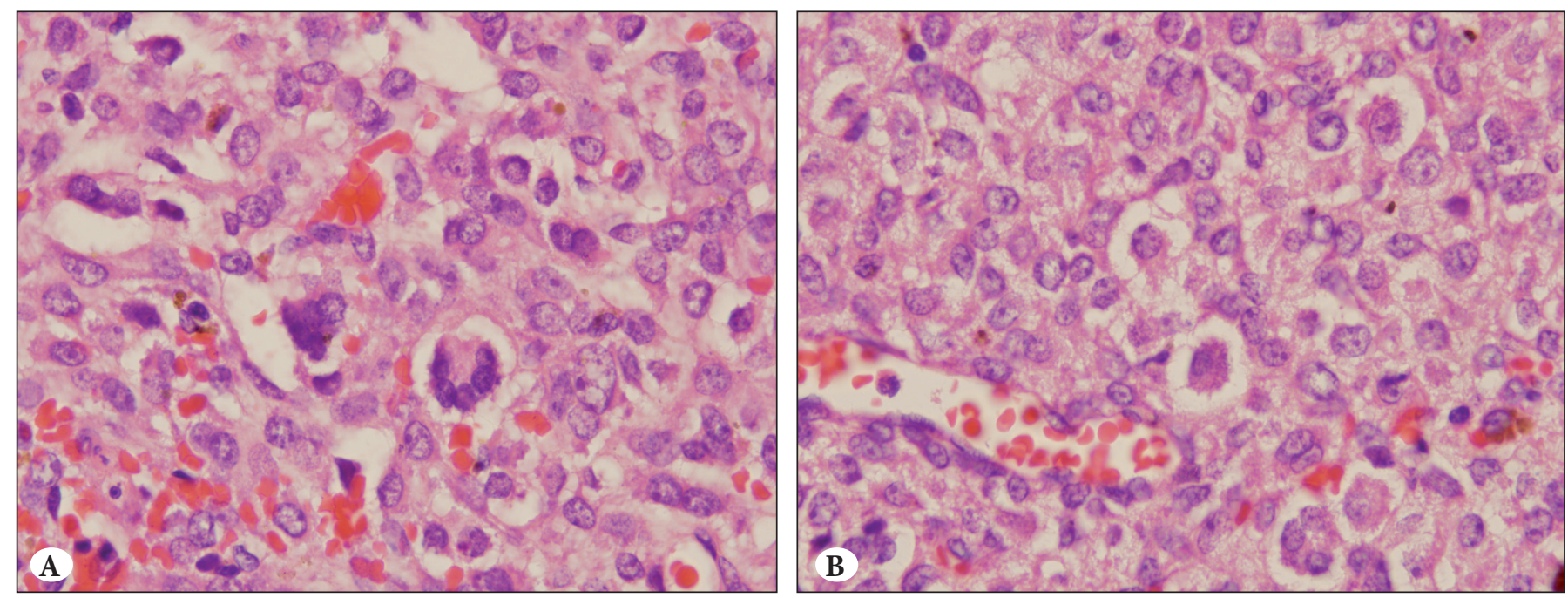

Figure 3: Multinucleated (A) and 'spider like' (B) giant tumor cells (H\&E, x1000).

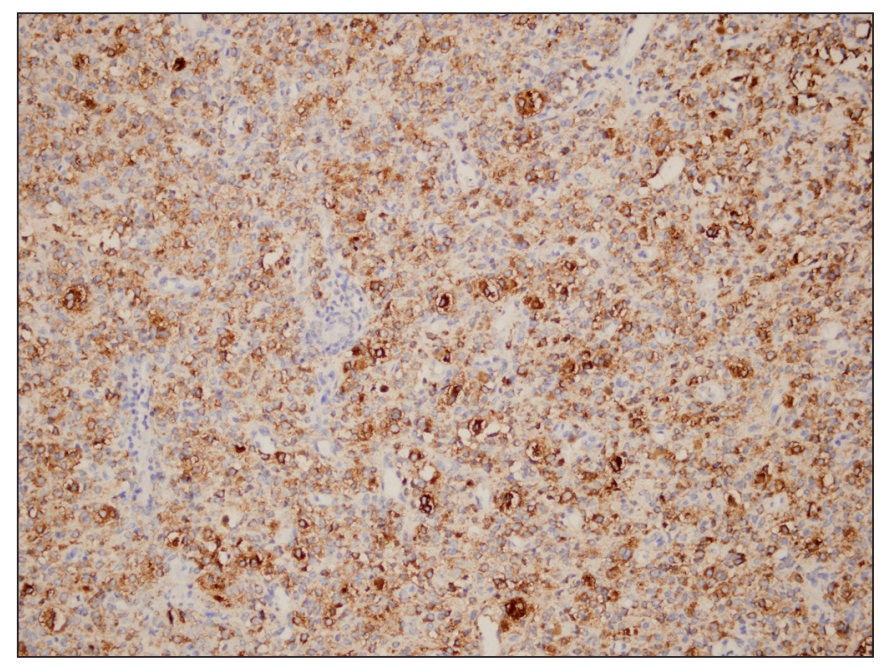

Figure 4: Tumor cells diffusely positive with HMB45 (DAB, x200).

immunophenotypical resemblance to perivascular epithelioid cells of AML, CCST and myomelanocytic tumors of the falciform ligament $(3,7)$. HMB45 positivity has been reported in some uterine smooth muscle and stromal tumors, and normal myometrium, but this positivity was generally focal and weak (3). Because PEComa has immunophenotypic and histopathologic features in common with epithelioid smooth muscle tumors, differential diagnosis may be problematic. In the past, this tumor has been designated PEComa, if the HMB45 positive cells are around the vascular structures. However, the definition has expanded in recent years, with all HMB45 positive epithelioid tumors now included in the definition of PEComa, whether or not there is perivascular distribution (8). Although some authors do not agree that
PEComa is a distinct entity, if the tumor is related to TSC and LAM, the occurrence of multinucleated giant cells and 'spider like' cells are indicative of PEComa under the current concept. A delicate capillary network and cytokeratin negativity also indicate of PEComa (9).

Eight cases of cervical PEComa have been reported (4, 1015). Clinical findings, treatment and follow-up of these cases are presented in Table I. In the present case, the patient was treated with total hysterectomy and bilateral salphingooopherectomy and through three years of checkups there was no recurrence.

PEComas are related to TSC, which is a genetic disorder attributable to the absence of the TSC1 (9q34) or TSC2 (16p13.3) genes. Clinically, it is characterized by mental retardation, seizures, intellectual disability and some tumors, such as cardiac rhabdomyomas, AMLs, subependymal giant cell tumors, cutaneous angiofibromas and LAM. Similar absences of the TSC genes are indicated in some PEComas when related to TSC, and in sporadic cases (1). According to the reported cases, the presence of PEComa with the tuberous sclerosis complex varies between 6-9\% $(11,14)$. Schoolmeester et al. investigated the clinical and pathological features of 16 gynecological PEComa cases, and 1 had a history of TSC (16). In the present study, the cervical PEComa was also associated with TSC and therefore represents the second cervical PEComa case associated with TSC.

Owing to the rarity of PEComas, it is not yet possible to produce a prognostic classification and to predict the biological behavior of these tumors. Folpe et al. reported 26 cases of PEComa in soft tissue and the female reproductive 
Table I: Literature review of cervical PEComa

Age ${ }^{*}$ TSC Diameter and localization of mass

Case 1

(Natella et al, 2013

52 No $12 \mathrm{~cm}$ mass in cervix
Treatment

Radical pelvectomy front

and rear with removal

of the uterus, vagina, bladder and anal canal + Adjuvant radiotherapy

Total hysterectomy and bilateral salphingooopherectomy

Radical Hysterectomy

Bilateral Salpingo-

oopherectomy+ External Disease-free at 3 beam irradiation and immunotherapy

Case 3

(Bradshaw et al, 2010)

46 No $3-4 \mathrm{~cm}$, localized to cervix

Follow-up

12 months

follow-up, no

recurrence

Disease-free at 1 year

years

After the third operation, 12 months follow-up, no recurrence the second operation

\begin{tabular}{lcclll}
\hline $\begin{array}{l}\text { Case } 5 \\
\text { (Azad et al, 2006) }\end{array}$ & 25 & No & $\begin{array}{l}\text { Anterior lip of cervix fungating } \\
\text { growth }\end{array}$ & $\begin{array}{l}\text { Radical hysterectomy and } \\
\text { lymphadenectomy }\end{array}$ & Not available \\
\hline $\begin{array}{l}\text { Case 6 } \\
\text { (Folpe et al, 2005) }\end{array}$ & 48 & No & 2 cm cervical mass & $\begin{array}{l}\text { Local excision }+ \\
\text { Adjuvant radiotherapy }\end{array}$ & $\begin{array}{l}\text { 21 months } \\
\text { follow-up, no } \\
\text { recurrence }\end{array}$ \\
\hline $\begin{array}{l}\text { Case } 7 \\
\text { (Folpe et al, 2005) }\end{array}$ & 28 & No & $3 \mathrm{~cm}$ cervical mass & $\begin{array}{l}\text { Hysterectomy + Lymph } \\
\text { node dissection }\end{array}$ & $\begin{array}{l}36 \text { months } \\
\text { follow-up, no } \\
\text { recurrence }\end{array}$ \\
\hline $\begin{array}{l}\text { Case 8 } \\
\text { (Fadare et al, 2004) }\end{array}$ & 41 & Yes & $\begin{array}{l}2.2 \mathrm{~cm} \text { mass in cervix } \\
\text { intraabdominal PEComatosis }\end{array}$ & $\begin{array}{l}\text { Total hysterectomy and } \\
\text { bilateral salphingo- } \\
\text { oopherectomy }\end{array}$ & $\begin{array}{l}35 \text { months } \\
\text { follow-up, no } \\
\text { recurrence }\end{array}$ \\
\hline Our Case & 41 & Yes & $\begin{array}{l}4 \text { cm cervical mass, intraabdominal } \\
\text { PEComatosis, cutaneous macula, } \\
\text { epileptic seizures, intellectual } \\
\text { disability }\end{array}$ & $\begin{array}{l}\text { Total hysterectomy and } \\
\text { bilateral salphingo- } \\
\text { oopherectomy }\end{array}$ & $\begin{array}{l}36 \text { months } \\
\text { follow-up, no } \\
\text { recurrence }\end{array}$ \\
\hline
\end{tabular}

*TSC: Tuberous Sclerosis Complex

tract. Of these patients, 24 were followed up (mean 30 months) and metastasis was detected in 8 patients. Folpe et al. proposed criteria to classify these tumors as 'benign', 'uncertain malignancy potential' and 'malignant'. In the same research, they reported a meaningful relationship between tumor size $(>5 \mathrm{~cm})$, mitotic activities $(>1 / 50$ HPF), necrosis, high nuclear grade and infiltrative growth pattern with aggressive behavior (14). Schoolmeester et al. investigated the clinical and pathological features of 16 gynecological PEComa cases (mean follow-up 26 months) and they suggested a modified classification system; namely, if there are 4 or more unfavorable histological findings (size $\geq 5 \mathrm{~cm}$, mitosis $\geq 1 / 50 \mathrm{HPF}$, significant nuclear atypia, necrosis, lymphovascular invasion), the tumor is classified as malignant. If none of criteria are met, the tumor is classified as benign. If the tumor meets 1 to 3 of the criteria, it is difficult to predict the behavior of the tumor. Therefore, it is classified as benign or of uncertain malignancy potential' (16). According to the modified system, our case had one unfavorable feature (focal necrosis) for aggressive behavior. However, there was no evidence of recurrence or metastasis after three years of regular checkups.

In summary, this case is reported to increase awareness among pathologists of the need for inclusion of PEComa in the differential diagnosis of epithelioid uterine mesenchymal tumors because their histopathological criteria for predicted biological behavior and classification are different from epithelioid smooth muscle tumors. Given the small series of reported cases, the most effective 
treatment approach for uterine PEComa is also uncertain. Large numbers of cases with long duration follow-up of their clinical behavior are required to confirm the effective management and prognostic classification of this tumor. Based on limited current data, uterine and cervical PEComas should be considered tumors of uncertain malignancy potential. They should be monitored for a long period because of their potential for local recurrence and metastasis. At least some of these tumors, as in our case, have a close relationship with TSC. It is therefore important to recognize PEComa in the evaluation and diagnosis of the other components of TSC.

\section{ACKNOWLEDGEMENT}

The authors thank Gregory T. Sullivan of the School of Geography, Planning and Environmental Management at the University of Queensland in Brisbane, Australia for editing the English in an earlier version of this manuscript.

\section{REFERENCES}

1. Martignoni G, Pea M, Reghellin D, Zamboni G, Bonetti F. PEComas: the past, the present and the future. Virchows Arch. 2008;452: 119-32.

2. Folpe AL. Neoplasms with perivascular epithelioid cell differentiation (PEComas). In: Fletcher CDM, Unni KK, Mertens F, editors. World Health Organization Classification of Tumors: Pathology and Genetics of Tumors of Soft Tissue and Bone. Lyon: IARC Pres; 2002. 221-2.

3. Fukunaga M. Perivascular epithelioid cell tumor of the uterus: Report of four cases. Int J Gynecol Pathol. 2005;24:341-6.

4. Natella V, Merolla F, Giampaolino P, Bifulco G, Mainenti PP, Insabato L. A huge malignant perivascular epithelioid cell tumor (PEComa) of the uterine cervix and vagina. Pathol Res Pract. 2014;210:186-8

5. Pea M, Bonetti F, Zamboni G, Martignoni G, Riva M, Colombari R, Mombello A, Bonzanini M, Scarpa A, Ghimenton C, et al. Melanocyte-marker-HMB-45 is regularly expressed in angiomyolipoma of the kidney. Pathology. 1991;23:185-8.
6. Bonetti F, Pea M, Martignoni G, Doglioni C, Zamboni G, Capelli P, Rimondi P, Andrion A. Clear cell (sugar) of the lung is a lesion strictly related to angiomyolipoma - the concept of a family of lesions characterized by the presence of the perivascular epithelioid cells (PEC). Pathology. 1994;26:230-6.

7. Folpe AL, Goodman ZD, Ihsak KG, Paulino AF, Taboada EM, Meehan SA, Weiss SW. Clear cell myomelanocytic tumor of the Falciform ligament/ligamentum teres: A novel member of the perivascular epithelioid claer cell family of tumors with a predilection for children and young adults. Am J Surg Pathol. 2000;24:1239-46.

8. Vang R, Kempson RL. Perivascular epithelioid cell tumor ('PEComa') of the uterus: A subset of HMB-45-positive epithelioid mesenchymal neoplasms with an uncertain relationship to pure smooth muscle tumors. Am J Surg Pathol. 2002;26:1-13.

9. Toledo G, Oliva E. Smooth muscle tumors of the uterus: A practical approach. Arch Pathol Lab Med. 2008;132:595-605.

10. Yang W, Li G, Wei-qiang Z. Multifocal PEComa (PEComatosis) of the female genital tract and pelvis: A case report and review of literature. Diag Pathol. 2012;7:23.

11. Bradshaw MJ, Folpe AL, Croghan GA. Perivascular epithelioid cell neoplasm of the uterine cervix: Unusual tumor in an unusual location. Rare Tumors. 2010;2:56.

12. Yamamoto E, Ino K, Sakurai M, Takigawa S, Iwase A, Kikkawa F Fertility-sparing operation for recurrence of the uterine cervical perivascular epithelioid cell tumor. Rare Tumors. 2010; 2: 26.

13. Azad NS, Aziz AB, Pervez S, Kayani N. Uterine perivascular epithelioid cell tumor presenting as a cervical mass. J P Med Assoc. 2006;56:83-4.

14. Folpe LA, Mentzel T, Lehr HA, Fisher C, Balzer BL, Weiss SW. Perivascular epithelioid cell neoplasm of soft tissue and gynecologic origin, clinopathologic study of 26 cases and review of the literature. Am J Surg Pathol. 2005;29:1558-75.

15. Fadare O, Parkash V, Yilmaz Y, Mariappan MR, Ma L, Hileeto D, Qumsiyeh MB, Hui P. Perivascular epithelioid cell tumor (PEComa) of the uterine cervix associated with intraabdominal "PEComatosis": A clinicopathological study with comparative genomic hybridization analysis. World J Surg Oncol. 2004; 2: 35.

16. Schoolmeester JK, Howitt BE, Hirsch MS, Dal Cin P, Quade BJ, Nucci MR. Perivascular epithelioid cell neoplasm (PEComa) of the gynecologic tract: Clinicopathologic and immunohistochemical characterization of 16 cases. Am J Surg Pathol. 2014; 38: 176-88. 